\title{
An Service oriented XL-BPMN Metamodel and Business Modeling Process
}

\author{
Chee-Yang Song ${ }^{*} \cdot$ Eun-Sook Cho ${ }^{++}$
}

\begin{abstract}
The business based existing BPMN model is a lack of service oriented modeling techniques. Therefore, it requires a layered technique of service oriented business modeling so that can meet the design for a complex application system, developing a system based on SOA. In order to enhance reusability and modularity of BPMN business model, this paper proposes a metamodel and business modeling process based on this metamodel that can hierarchically build a BPMN model. Towards this end, the XL-BPMN metamodel hierarchically established based on MDA and MVS styles are first defined. Then a BPMN service modeling process is constructed based on modeling elements of this metamodel according to the modeling phases. Finally, the result of a case study in which the proposed method is applied to an online shopping mall system is discussed. With the use of well-defined metamodel and modeling process, it is hoped that it can be shown that a service dominated and layered BPMN business model can be established, and that the modularity and reusability of the constructed BPMN business model can be maximized.
\end{abstract}

Keywords : Business Process, BPMN, Metamodel, MDA, MVC, Service Oriented Modeling, Layered Modeling

\section{서비스 지향 XL-BPMN 메타모델과 비즈니스 모델링 프로세스}

\author{
송 치 양 $\cdot$ 조 은 숙 ${ }^{++}$
}

요 약

업무에 초점을 둔 BPMN 모델은 서비스 지향 비즈니스 모델링에 한계점을 안고 있다. 이에, SOA 기반의 시스템 개발을 위해 서비스 수준 에서 복잡한 응용 시스템을 디자인할 수 있는 서비스 지향의 비즈니스 모델링 기법이 요구된다. 본 논문은 BPMN 비즈니스 모델의 모듈성과 재사용성을 향상시키기 위해, 서비스 지향으로 BPMN 모델을 계층적으로 구축할 수 있는 메타모델과 이에 기반한 비즈니스 모델링 프로세스를 제시한다. 이를 위해, BPMN 모델의 모델링 요소들을 MDA와 MVC 패턴에 의해 계층화하고 서비스 지향의 모델링을 위한 확장된 XL-BPMN 메타모델을 정의한다. 이 메타모델의 모델링 요소를 이용해서, 모델링 단계에 의한 $\mathrm{BPMN}$ 서비스 모델링 프로세스를 정립한다. 이 기법은 온라 인쇼핑몰시스템의 비즈니스 모델링에 사례로서 적용되고 평가되어진다. 잘 정의된 메타모델과 모델링 프로세스를 통해, 서비스 중심의 BPMN 비즈니스 모델을 생성할 수 있고, BPMN 모델의 모듈성을 증진시킬 수 있으며, 또한 독립적으로 재사용 가능한 모델의 수를 극대화할 수 있다.

키워드 : 비즈니스 프로세스, BPMN, 메타모델, MDA, MVC, 서비스 지향 모델링, 계층적 모델링

\section{1. 서 론}

최근 응용 시스템의 개발은 서비스 지향의 $\mathrm{SOA}$ (ServiceOriented Architecture)[1-5]에 기반하는 추세이다. 통상, 어 플리케이션의 개발은 비즈니스 모델링, 서비스 모델링, 그리 고 컴포넌트 모델링을 거쳐 실제 구현의 개발 프로세스를

※ 이 논문은 2012년도 정부(교육과학기술부)의 재원으로 한국연구재단의 기초연구사업 지원을 받아 수행된 것임(2012002161).

† 정 회 원 경북대학교 컴퓨터정보학부 부교수

† 정 회 원: 서일대학 컴퓨터소프트웨어학과 부교수

논문접수: 2012 년 11 월 19 일

수 정 일 : 1차 2013년 1월 4일

심사완료:2013년 1월 4일

* Corresponding Author:Eun-Sook Cho(escho@seoil.ac.kr)
수행하게 된다. 따라서, 상위 비즈니스 서비스의 프로세스를 어떻게 구성하느냐에 따라 사용되는 하부의 컴포넌트 수가 달라 질 수 있다. 즉, 최적의 서비스 프로세스를 설계해야 최소의 컴포넌트로 시스템을 구축할 수 있다. 그래서, 복잡 한 시스템의 비즈니스 프로세스를 모델링할 수 있고, 최적 화된 비지니스 모델을 설계할 수 있는 체계적이고 구체적 지침을 제공하는 서비스 중심의 비지니스 모델링 프로세스 가 필요하다.

대상 도메인의 비즈니스 프로세스 디자인을 위한 대표적 인 모델링 도구인 $\mathrm{BPMN}$ (Business Process Modeling Notation)[6-7] 모델은 OMG(Object Management Group)의 표준으로서 비즈니스 프로세스를 디자인 할 수 있는 표준화 
된 그래픽 표기법이다. $\mathrm{BPMN}$ 은 $\mathrm{SOA}$ 표현을 위한 최적의 표현기법이라 평가받고 있다. 기존, $\mathrm{BPMN}$ 을 이용한 비즈니 스 모델링 방법들[8-9]은 그 사용법과 적용 사례는 풍부하 나, 업무에 초점을 둔 비즈니스 프로세스 모델링의 한계점 을 갖는다. 이에, SOA 기반의 복잡한 서비스 시스템을 디자 인할 수 있도록 서비스 차원에서 $\mathrm{BPMN}$ 의 계층적 모델링 접근에 대해서는 구체적인 가이드를 제시하고 있지 않다. 단순히, activity의 process가 sub-process를 갖는 개념하에, 상위 BPMN 모델이 하부 BPMN 모델을 복합(composition) 관계로서 표현한다. 따라서, 개발 단계의 추상화 수준에 따 라 $\mathrm{BPMN}$ 모델을 모델링할 수 있는 계층적 모델링을 제공 하지 않아, 복잡한 업무처리를 계층적 비지니스 구조 모델 로 표현하기가 어렵고, 생성된 모델의 재사용 가능한 비즈 니스 모델의 수가 적게 된다. 그 이유는 $\mathrm{MDA}$ (ModelDriven Architecture)[10-13]와 MVC(Model View Controller)[14-15]에 기반하여 상위의 추상적 모델링에서 하 위의 구현적 플랫폼에 독립적인 모델링에 이르기까지 범주 를 포함하는 계층화된 모델링 프로세스를 제공하지 못하기 때문이다. 이후, 이를 해결하기 위해, 서비스 지향의 비즈니 스 모델링에 관련 연구들로서, $\mathrm{BPDS}-\mathrm{BB}[5]$ (가칭)와 MINERVA[16]에서 서비스 지향 BPMN 비즈니스 모델링을 제공하나, $\mathrm{MDA}$ 와 $\mathrm{MVC}$ 기반의 모델링 방법을 지원하지 않 는다. ARIS[17]에서 서비스 패러다임에 따라 $\mathrm{MDA}$ 와 $\mathrm{MVC}$ 기반 비즈니스 모델링을 제공하나, BPMN을 대상으로 하지 않으며, 메타모델의 모델링 요소들에 기반의 모델링 프로세 스를 갖고 있지 않다.

$\mathrm{MDA} / \mathrm{MVC}$ 기반 $\mathrm{BPMN}$ 서비스 모델링 접근의 필요성은 "관심의 분리(separation of concerns)"의 설계원리에 입각하 여 $\mathrm{MDA}$ 와 $\mathrm{MVC}$ 패턴에 의해 계층적으로 분리된 $\mathrm{BPMN}$ 모델들을 생성함으로서, 재사용 가능한 독립된 모듈성이 강 한 비즈니스 모델의 수를 극대화하기 위함이다. 특수화된 다양한 비즈니스 영역별 그리고 개발의 추상화 수준별로 공 통된 $\mathrm{BPMN}$ 모델을 계층화하여 구축하고, 이들을 하부를 구성하는 실행 컴포넌트까지 연계하여 CASE Tool로 제공 된다면, 분석모델, 설계모델 및 실행 모듈의 재사용을 향상 시켜 개발의 노력을 최소화할 수 있다. 결국, $\mathrm{BPMN}$ 모델을 이용한 비즈니스 모델링 프로세스는 $\mathrm{SOA}$ 지향 $\mathrm{MDA}$ 와 $\mathrm{MVC}$ 의 계층적 패러다임을 지원하는 $\mathrm{UML}$ 기반의 객체 및 컴포넌트 지향 개발 방법들[18-19]처럼, 성숙되어 있지 않 다. 그래서, $\mathrm{BPMN}$ 모델의 구조물을 구성하는 범용적 및 공 통적 모델링 요소들로 $\mathrm{MDA}$ 에 의해 정의된 계층적 메타모 델이 필요하고 이 메타모델의 모델링 요소들을 사용한 서비 스 기반 BPMN 비즈니스 모델링 프로세스가 요구된다.

본 논문은 개발 대상 도메인의 상위 시스템 레벨에서 하 위 단위 서비스 수준에 이르는 $\mathrm{BPMN}$ 모델의 계층적이고, 확장적인 XL(eXtended/Layered)-BPMN 메타모델과 서비스 기반 $\mathrm{BPMN}$ 비즈니스 모델링 프로세스를 제시한다. 먼저, XL-BPMN 메타모델은 $\mathrm{MDA}$ 지향의 $\mathrm{CIM}$ (Conceptual
Independent Model), PIM(Platform Independent Model) 및 $\mathrm{PSM}$ (Platform Specific Model) 패턴의 적용, 그리고 비즈니 스 개발의 추상화 정도(모델링 대상의 크기(granularity))에 따라 사용되는 모델링 요소들을 가미하여, 정형화되고 계층 적으로 정의한다. 또한, 이 메타모델에 $\mathrm{MVC}$ 패턴을 적용해 서, 각 모델링 단계별 비즈니스 서비스들(즉, Model service, View service, Controller service)을 분리하여 이차원(수준별 및 계층적)적으로 모델링할 수 있도록 정의한다. 즉, 기존 $\mathrm{BPMN}$ 메타모델의 구조물에 서비스 수준의 모델링을 가능 하게 하고, $\mathrm{MDA}$ 및 $\mathrm{MVC}$ 방식을 적용할 수 있도록, 추가 적 모델링 요소들을 가미하여 확장된 $\mathrm{XL}-\mathrm{BPMN}$ 메타모델 을 정의한다. 아울러, 비즈니스 모델링 작업에 적용하기 위 해, $\mathrm{XL}-\mathrm{BPMN}$ 메타모델에 기반해서 $\mathrm{CIM} / \mathrm{PIM}$ 모델링 단계 (비지니스 서비스 모델링, 시스템 서비스 모델링)로 서비스 지향 $\mathrm{BPMN}$ 비즈니스 프로세스를 정립한다. 이로서, 서비스 중심의 모듈성이 강한 $\mathrm{BPMN}$ 비즈니스 모델을 생성할 수 있고, 정형화된 $\mathrm{BPMN}$ 메타모델을 이용한 패턴별 비즈니스 모델의 생성은 재사용성과 독립적 재사용 가능한 모델의 수 를 향상시켜준다.

본 논문의 구성은 2장 관련연구에서 서비스 지향의 $\mathrm{BPMN}$ 모델링 방법들을 분석한다. 3장에서 확장된 $\mathrm{BPMN}$ 모델과 서비스 지향 모델링 프로세스를 기술한다. 4장은 OSS(Online Shopping System)을 가지고 사례적용을 다루 며, 5장은 기존 방법 대비 제시방법을 비교평가한다.

\section{2. 관련 연구}

\subsection{BPMN 비지니스 모델링}

비즈니스 프로세스를 모델링하기 위한 대표적인 모델들로 서 BPMN, $\mathrm{EPC}($ Event-driven Process Chain), Petri-Net, $\mathrm{ICN}$ 등이 있다. $\mathrm{OMG}$ 의 표준으로 널리 사용되는 $\mathrm{BPMN}[6-7]$ 은 비즈니스 프로세스를 디자인 할 수 있는 표 준화된 시각적 표기법이다. $\mathrm{BPMN}$ 으로 모델링된 서비스의 비즈니스 모델은 통상, BPEL(Business Process Execution Language)로 패턴별(순차, 분기 등) 변환, 명세되고, 이 $\mathrm{BPEL}$ 은 $\mathrm{BPM}$ (Business Process Management) 실행엔진을 통해 비즈니스 서비스의 프로세스가 수행된다[9]. BPMN은 $\mathrm{UML}$ 의 활동 모델(Activity diagram)과 유사하나, 보다 강 력한 표현력과 확장성을 가지고 있다. $\mathrm{BPMN}$ 의 주요한 모 델링 요소로서 흐름객체(Flow Object), 연결객체(Connecting Object), 스윔레인(Swimlane), 부가객체(Artifact)로 구성되 어 있다. 이를 지원하는 도구로서 50여개가 존재하며, 대표 적 도구로 국외의 Pegasystems SmarBPM Suite, BEA AquaLogic BPM Designer, IBM WebSphere Business Modeler 그리고 국내의 HandySoft의 BizFlow가 있다.

$\mathrm{BPMN}$ 모델을 정의한 $\mathrm{BPMN}$ 메타모델에 대해 살펴보자. 먼저, BPMN V1.0의 메타모델인 [20] 그리고 BPMN 모델링 지원도구 구축을 지원하기 위해 실행수준에서 제시한 메타 
Table 1. Study on verification and extension for BPMN model

\begin{tabular}{|c|c|c|}
\hline Method & Features & Proposed content \\
\hline $\begin{array}{l}\text { Validation checking } \\
\text { Of business process }\end{array}$ & $\begin{array}{l}\text { Validation for four anomalies based on } \\
\text { BPMN } \\
\text { Using of the } \pi \text {-calculus which the } \\
\text { representation of workflow pattem has } \\
\text { easy }\end{array}$ & $\begin{array}{l}\text { Utilizing the legacy studies for converting BPMN model into } \\
\pi \text {-calculus } \\
\text { Anomaly validation for single and mixed stream in BPMN } \\
\text { and its proving with } \pi \text {-calculus }\end{array}$ \\
\hline $\begin{array}{l}\text { Design anomalies in } \\
\text { BPM }\end{array}$ & $\begin{array}{l}\text { Syntactic and semantics identification } \\
\text { for BPMN model }\end{array}$ & $\begin{array}{l}\text { Identification of syntactic anomalies in BPMN } \\
\text { (Using mistaken trigger, and etc) } \\
\text { Identification of structual anomalies in BPMN } \\
\text { (Deadlock, endless loop, synchronizing) } \\
\text { Identification of semantics anomalies in BPMN }\end{array}$ \\
\hline $\begin{array}{l}\text { Extending the } \\
\text { abstraction } \\
\text { capability of BPMN }\end{array}$ & $\begin{array}{l}\text { P Providing the abstraction capability of } \\
\text { BPMN model on various view among } \\
\text { stakeholders } \\
\text { Extending the horizontal abstraction } \\
\text { scope of BPMN using super edge concept }\end{array}$ & $\begin{array}{l}\text { Defining the abstract and concrete view of BPMN model } \\
\text { Horizontal abstraction technique by super-node and } \\
\text { super-edge } \\
\text { Defining the order independency of vertical abstraction } \\
\text { operation }\end{array}$ \\
\hline $\begin{array}{l}\text { BPMN extension for } \\
\text { security } \\
\text { requirements }\end{array}$ & $\begin{array}{l}\text { Building the security business process } \\
\text { model for business } \\
\text { Modeling method by embedding the } \\
\text { security requirements In early phase }\end{array}$ & $\begin{array}{l}\text { Extended BPMN metamodel for considering the security } \\
\text { requirements } \\
\text { Defining the concepts and notation of security modeling } \\
\text { elements for Non repudiation, AttackHamDetection, Integrity } \\
\text { Privacy, Access control, Security role, Security }\end{array}$ \\
\hline
\end{tabular}

모델인 [21]가 있다. 최근, OMG BPMN metamodel[7] (V2.0 Beta version)은 구성 요소들을 metaclass들에 의해 체계적 인 패키지 속으로 조직화하여 정의했다. 핵심 요소별(가령, event, artifact, flow 등)로 구문(syntax)와 시멘틱 (semantics)에 의해 클래스 모델(class model)로 정의하고 있다. 그러나, 상위 패키지 모델과 하위 요소별 클래스 모델 간의 연계 구조 및 의미가 복잡하고, 메타모델에 기반한 프 로세스를 제시하고 있지 않아 사용이 용이치 않다. 그 외 연구로서, $\mathrm{BPMN}$ 모델 자체의 검증[22-23]과 $\mathrm{BPMN}$ 표현력 확장[24-25]있는데, 그 내역은 Table 1과 같다.

한편, $\mathrm{BPMN}$ 모델의 실행을 위한 $\mathrm{BPEL}$ 로의 $\mathrm{WSDL}$ 변 환 및 명세에 대한 기법[26-27] 등이 있다. 이에, 서비스 지 향 비즈니스 프로세스를 모델링하기 위한 $\mathrm{BPMN}$ 표준, 개 발 프로세스, 타 언어로의 변환, 지원도구 등에 대한 연구는 성숙되어 있다.

\section{2 서비스 지향 비즈니스 모델링}

인터넷의 초고속화와 IT 기술의 성장에 힘입어 산업간, 이질적 미디어간 혹은 이기종 환경간의 융합화가 가속화됨 에 따라, 서비스는 점차 복잡화, 대형화 및 다양화되어 가고 있다. 이러한 이기종 환경에서 구현 기술로부터 독립적인 SOA[1-5] 혹은 SOC(Service Oriented Computing)[15]를 통 한 서비스 접근이 활성화되고 있다. SOA는 서비스 지향을 지원하는 IT 스타일 아키텍쳐로서, 전통적 프로그램 중심의 설계와 개발 방식에서 벗어나, 비즈니스 프로세스 관점에서 재사용 가능한 단위로 서비스를 설계, 개발함으로서 특정 프로세스나 서비스 변경, 외부 시스템과의 비즈니스 통합시, 효율적이고 신속한 대응이 가능하다. 이러한 SOA에 따른 어플리케이션 시스템의 서비스 구축은 도메인 업무에 초점 을 둔 상위의 비즈니스 모델링 부문과 시스템 기능에 기반 하는 하부의 소프트웨어 모델링 부문에 의해 수행된다. 즉, 비즈니스 모델링을 통해 업무 비지니스의 프로세스를 분석 하여 서비스를 도출하고, 소프트웨어 모델링을 통해 이 서
비스에 필요한 컴포넌트들을 식별하고 기존 컴포넌트를 재 사용하거나, CORBA(Common Object Request Broker Architecture), DCOM(Distributed Common Model), COM+, EJB(Enterprise Java Bean), J2EE(Java 2 Enterprise Edition), .NET 등의 분산 컴포넌트 플랫폼 환경을 사용해 서 새로이 컴포넌트를 구축하여 서비스를 구축한다. 소프트 웨어 모델링 부문은 전산학 학문영역에서, UML(Unified Modeling Language)을 사용해서 MDA(Model Driven Architecture)[10-13]와 MVC[14-15] 기반으로 계층적으로 컴포넌트를 생성하는 방법과 프로세스가 [18-19]와 같이 잘 체계화되어 있다. 소프트웨어 모델링 부문을 지원하기 위한 상용 개발 방법론으로 UP(Unified Process), SOUP(Service Oriented Unified process) 및 마르미 III 등이 있다. 반면, 비즈니스 모델링 부문은 산업공학 혹은 경영정보학 학문영 역에서, 비즈니스 영역을 추출하고, 비즈니스 서비스를 식별 하여, $\mathrm{BPMN}$ 등을 사용해서 비즈니스 프로세스로 모델링 작업을 수행한다. BPMN 기반이 아닌 일반적인 비즈니스 모델링을 위한 개발 방법론으로 국외 $\mathrm{UMM}(\mathrm{UN} / \mathrm{CEFACT}$ Modeling Methodology)[28-29]과 IDEF(ICAM Definition, Integration Definition for Function Modeling)[30-31] 등, 그 리고 국내 $\mathrm{S}$ 사의 업무 프로세스 설계(FP 모델: Function Process)와 정보시스템 모델 설계의 작업 활동으로 구성된 $\mathrm{BPR} / \mathrm{ISP}$ 방법론이 있다.

한편, $\mathrm{BPMN}$ 을 사용한 서비스 지향 비즈니스 모델링에 관해서 살펴보자. BPDS-BB[5]은 BPMN을 사용해서 비즈니 스 모델링을 수행하고 이의 구현을 위한 기술 플랫폼으로 $\mathrm{SOA}$ 연계의 접근모형을 제시한다. 그러나, 서비스 지향의 구체적인 $\mathrm{BPMN}$ 모델링 방법을 제시하고 있지 않다. MINERVA[16]는 SOC 패러다임과 MDD(Model Driven Development) 기반의 BPMN 비즈니스 프로세스를 위한 MINERVA 프레임워크를 제시한다. 이는 플랫폼은 3차원 구조로서, 첫째 개념적 차원은 비즈니스 프로세스 모델링/서 비스 지향 모델링/서비스 지향 실행의 상위수준 구조, 둘째 
방법론적 차원은 비즈니스 모델링/요구분석/설계/구현 단계 에 따른 비즈니스 프로세스/서비스 식별.명세/서비스 구현, 셋째 이 프로세스를 지원하는 툴 차원으로 제시했다. 그러 나, $\mathrm{MDA} / \mathrm{MVC}$ 기반의 접근을 제공하지 않는다. ARIS[17] 는 $\mathrm{EPC}$ 과 $\mathrm{BPMN}$ 모델을 사용한 $\mathrm{SOA} / \mathrm{MDA}(\mathrm{CIM}$, $\mathrm{PIM}) / \mathrm{MVC}$ 기반의 ARIS 모델링 방법을 제시한다. 특히, $\mathrm{MDA}$ 기반의 정적/동적 및 내부/외부 관점에 의한 서비스 식별기법을 위한 SOA 메타모델을 다룬다. 그러나, 비즈니스 모델링 및 서비스 식별 방법이 $\mathrm{EPC}$ 메타모델의 모델링요소 를 대상으로 한다. 즉, $\mathrm{BPMN}$ 모델 대상의 비즈니스 서비스 모델링 방법과는 상이하다.

따라서, 이들의 비즈니스 모델링 개발방법에서는 $\mathrm{MDA}$ 와 $\mathrm{MVC}$ 에 기반한 개발의 추상화 수준에 따른 서비스 중심의 계층적인 개발 프로세스가 미약하다. 이로서, 생성된 비즈니 스 모델 및 시스템 서비스 모델의 재사용이 활성화되지 못 함으로서 따른 전체적인 시스템 개발의 생산성의 저하를 야 기한다. 또한, 비즈니스 모델링과 소프트웨어 모델링 작업간 에 조직적으로 상호 연계, 통합된 개발 프로세스를 지원하 고 있지 않다.

결과적으로, 기존 방법들의 문제점은 생성된 $\mathrm{BPMN}$ 비즈 니스 모델의 재사용성을 향상시키기 위해, $\mathrm{BPMN}$ 모델을 구축함에 있어 개발의 추상화 수준에 따른 계층적이고 모델 기반의 모델링 접근에 관한 연구가 미약하다. 즉, $\mathrm{BPMN}$ 메 타모델의 모델링 요소들과 그들 간의 구문적 관계에 기반해 서, $\mathrm{BPMN}$ 모델을 추상화 정도에 따른 $\mathrm{MDA}$ 의 $\mathrm{CIM}$ 및 $\mathrm{PIM}$ 방식에 의한 독립적 $\mathrm{BPMN}$ 모델들의 구축 그리고 어 플리케이션 아키텍쳐의 $\mathrm{MVC}$ 패턴에 의한 분리 독립된 $\mathrm{BPMN}$ 모델을 디자인을 위한 방법이 결여되어 있다. 따라 서, 모델링 단계의 수준별/영역별로 독립적인 재사용 가능한 많은 비즈니스 모델들을 생성할 수 없으므로, 작성된 $\mathrm{BPMN}$ 모델의 재사용에 저해가 되고 있다. 아울러, 계층적 접근의 부재는 복잡한 비즈니스 모델의 모델링 작업을 어렵 게 만든다. 이것은 정형화되고 계층화된 $\mathrm{BPMN}$ 모델의 메 타모델 및 모델링 프로세스를 지원하지 않기 때문이다.

\section{3. 서비스 기반 BPMN 메타모델 및 프로세스}

본 논문은 복잡한 비즈니스 서비스를 효과적으로 모델링 하기 위해서 추상적/계층적 접근에 의한 비즈니스 서비스의 모델링 방법을 제공하는 것이다. 목표는 다양한 비즈니스 응용분야에 적용이 가능한 범용적이고 일원화된 서비스 지 향의 계층적 $\mathrm{BPMN}$ 모델링 기법에 초점을 둔다. 따라서, $\mathrm{MDA} / \mathrm{MVC}$ 에 준거하여 $\mathrm{BPMN}$ 모델의 모델링 요소들이 개 발 단계에 따라 상이하게 적용되는 계층적 접근을 제시한 다. 제시 내용은 다음과 같다.

- $\mathrm{BPMN}$ 모델의 계층성을 가진 확장된 메타모델 정의(CIM, PIM, PSM)
- 메타모델 사용의 $M D A$ 기반 계층적 서비스 모델링 프로세스 정립(CIM, PIM)

- $M V C$ 기반의 서비스 분리 모델링

연구 접근의 범주 모델은 Fig. 1 과 같이, $\mathrm{BPMN}$ 모델의 구조물을 계층화하여 메타모델로 정의하고 이 메타모델에 기반하여 BPMN 서비스 모델링 프로세스를 정립한다. Fig. 1 에서 회색 굵은 박스 부문이 본 논문에서 제시하는 것이다.

본 접근을 위한 개념(concept)들[19]로 메타모델 (metamodel), 계층(hierarchy), $\mathrm{MDA}$, 그리고 $\mathrm{MVC}$ 를 이용 한다. 메타모델은 BPMN 모델이 가진 추상적 구문(abstract syntax)을 정의하기 위해 사용한다. 계층은 생성된 비지니스 모델의 재사용성을 높이기 위해 메타모델과 모델링 프로세 스의 정의에 적용된다.

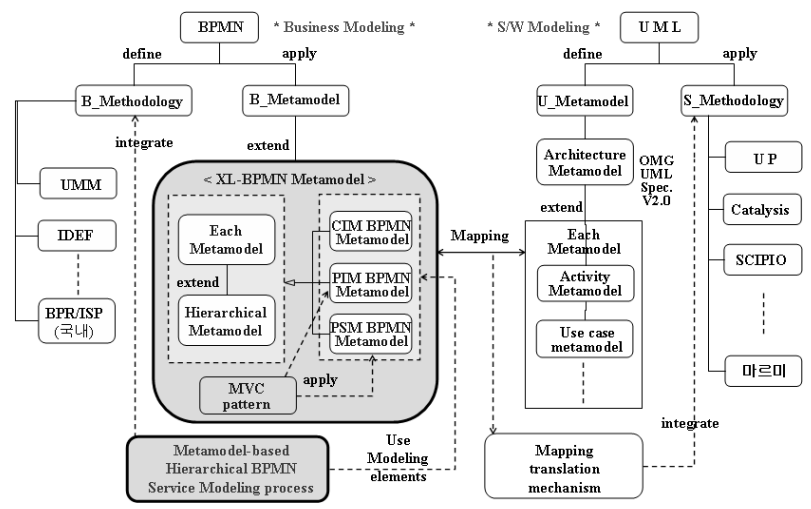

Fig. 1. Scope model of layred BPMN modeling approach

이것은 “관심의 분리" 원리에 기반하여 디자인 모델들을 분리하기 위한 계층적 구조로 조직화 해준다. 도메인의 크 기에 의한 계층화 수준은 시스템(system), 도메인 테스크 (domain task), 서비스(service) 층으로 분류한다. 반면, 추상 화에 의한 계층화 타입은 개발의 생명주기에 따라 개념적 수준의 CIM modeling phase, 명세적 수준의 PIM modeling phase로 구성한다. 계층화된 비즈니스 모델을 구축하기 위 한 $\mathrm{MDA}$ 는 구현 플랫폼을 고려하지 않는 모델의 분리, 생 성을 지원하는 제공하는 $\mathrm{PIM}$ 기술을 의미한다. $\mathrm{MVC}$ 는 클 라이언트측의 사용자 인터페이스에 대해, 서버측의 비즈니 스 로직 모델을 거쳐 데이터 모형에 관련시키기 위한 설계 방식이다. 즉, $\mathrm{M}$ 은 entity 클래스, $\mathrm{V}$ 는 $\mathrm{GUI}(G r a p h i c$ User Interface) 클래스, $\mathrm{C}$ 는 controller 클래스를 나타낸다. 이러 한 개념에 입각하여, 메타모델과 프로세스를 구축하기 위한 원리[19]는 다음과 같다.

- 계층적 $\mathrm{BPMN}$ 메타모델 정의

- $\mathrm{MDA}$ 와 $\mathrm{MVC}$ 패턴을 적용하여 계층적 메타모델을 정의한다.

- 계층적 메타모델의 구축은 필수적/실용적/범용적으로 사용되는 핵심 모델링 요소들과 그들 간의 관계 요소 
들을 가지고 $\mathrm{CIM} / \mathrm{PIM} / \mathrm{PSM}$ 모델을 구축토록 계층화 하여 정의한다.

- 계층적 모델링을 제공하기 위해, $\mathrm{BPMN}$ 모델이 가지 고 있는 모델링 요소들은 개발의 추상화 정도 혹은 어플리케이션의 크기에 따라 명확하게 계층화하여 정 의한다.

- 계층적 메타모델내 모델링 요소는 개발 단계가 구체 화될수록 추가, 확장된다.

- 계층적 $\mathrm{BPMN}$ 서비스 비즈니스 프로세스 구축

- 계층적 메타모델을 사용해서 2개 모델링 단계에 의해 모델링 절차를 정립한다. 즉, 비즈니스 서비스 (Business service) 그리고 시스템 서비스(System service)의 모델링 단계로 구성한다.

- 도메인 및 구현 플랫폼에 종속 여부에 따라, $\mathrm{MDA}$ 기반의 CIM과 PIM 패턴에 의해 모델을 구축한다.

- $\mathrm{MDA}$ 와 $\mathrm{MVC}$ 에 의해 생성된 산출물(비지니스 모 델)들은 단위 독립적 모델로서 재사용 될 수 있도 록 한다.

\section{$3.1 \mathrm{BPMN}$ 모델상의 서비스}

서비스 지향의 $\mathrm{BPMN}$ 모델을 디자인하기 위해, 서비스에 대한 정의 및 분류가 필요하다. 본 논문에서 서비스(혹은 비 즈니스 서비스)는 한 개의 재사용 가능한 독립적 업무 단위 혹은 기능을 의미하며, 업무 기능이 시작해서 종료되면 서 비스 작업이 완료되어야 한다(원자성, 단일성 보유). $\mathrm{BPMN}$ 모델에서 서비스 구성은 아래와 같다.

- 한 개 어플리케이션 시스템 = 도메인 테스크의 집합체

- 한 개 도메인 테스크 = 비즈니스 서비스의 집합체

- 한 개 비즈니스 서비스 $=$ 한 개 서비스

이때, 한 개 서비스별로 $\mathrm{MDA}$ 및 $\mathrm{MVC}$ 패턴에 의해 다 수의 $\mathrm{BPMN}$ 모델들이 작성된다. 이러한 서비스 구성과 유 형을 고려해서 서비스 메타모델을 정의한 것이 Fig. 2이다. Fig. 2에서 "coarse-grained service"는 상위 서비스를 의미 하며, "fine-grained service"는 상위 서비스에 복합 (composite)의 관계를 갖는 하위서비스를 나타낸다.

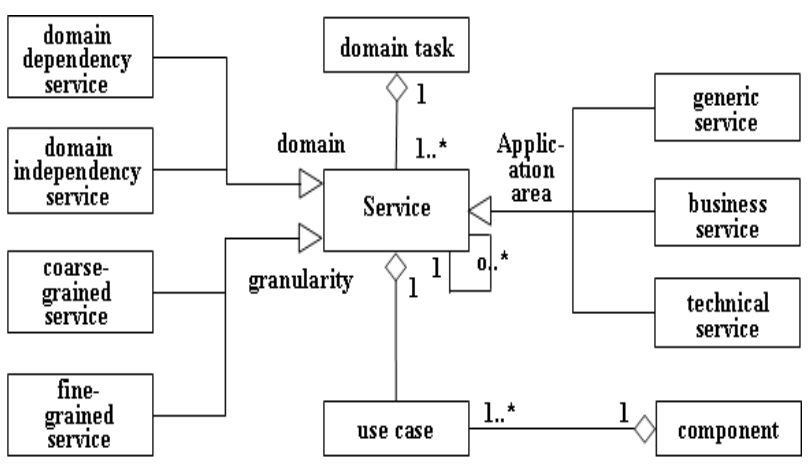

Fig. 2. Service metamodel

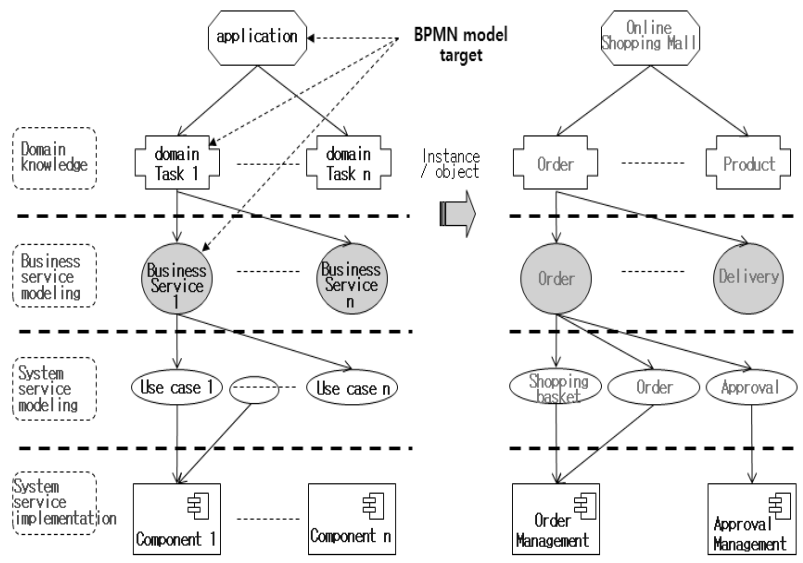

Fig. 3. Service construction of online shopping mall system

모델링 단계에 따른 Fig. 2의 메타모델에 기반한 "온라인 쇼핑몰시스템” 대상의 서비스 구축 예가 Fig. 3이다.

\subsection{MDA/MVC 기반 계층적 BPMN 메타모델}

$\mathrm{BPMN}$ 모델을 정의하기 위한 메타모델은 두 가지로 정 립한다. 먼저, $\mathrm{BPMN}$ 모델을 정의한 $\mathrm{OMG}$ 표준에 기반하여 $\mathrm{BPMN}$ 메타모델(Fig. 4)을 정의한다. 다음으로, 이 BPMN 메타모델에 서비스 기반의 확장된 XL-BPMN 메타모델(Fig. 6)을 정의한다.

\section{1) BPMN 메타모델}

$\mathrm{BPMN}$ 모델은 흐름 객체, 연결 객체, 스윔레인 및 부가 객체 등의 핵심 모델링 요소를 가지고, 구축 대상 도메인의 업무에 대해 비즈니스 프로세스(혹은 control flow)를 표현 하는 플로우챠트 타입(flowchart-type) 다이어그램이다. $\mathrm{OMG} \mathrm{BPMN}$ V1.0 표준[6-7]과 [9]에서 제시한 $\mathrm{BPMN}$ 모델 의 구조물을 구성하는 모델링 요소들에 근거하여 $\mathrm{BPMN}$ 모 델을 정의한 기본적인 $\mathrm{BPMN}$ 메타모델이 Fig. 4이다.

\section{2) XL-BPMN 메타모델}

$\mathrm{BPMN}$ 모델에 $\mathrm{MDA}$ 기반 모델링 단계의 계층적 접근과 $\mathrm{MVC}$ 기반 어플리케이션 아키텍쳐의 분리적 접근을 제공하 기 위해, Fig. 4의 BPMN 메타모델에 모델링 요소들이 추가 되어야 하고, 이들을 계층화하여 확장된 메타모델로 정의되 어야 한다. Table 2 는 확장되고 계층화된 XL-BPMN 메타 모델을 정립하기 위한 모델링 대상, 모델링 방법 및 수준을 정립한 것이다.

Table 2에서, $\mathrm{MDA}$ 방식은 CIM과 PIM 패턴에 의해 3계 층 $\mathrm{BPMN}$ 메타모델로 정의한다. 즉, $\mathrm{CIM} \mathrm{BPMN}$ 메타모델 그리고 PIM BPMN 메타모델로 구성한다. 각 메타모델의 구 성은 개발 프로세스상에서 도메인 및 플랫폼의 종속여부에 따라 $\mathrm{BPMN}$ 의 기존 및 확장된 모델링 요소들을 가지고 메타 모델을 계층화하여 정의한다. MVC 패턴은 PIM BPMN 메타 모델에 모델링요소로 적용된다. 가령, $\mathrm{PIM} \mathrm{BPMN}$ 메타모델 의 $\mathrm{M} / \mathrm{V} / \mathrm{C}$ 모델링요소를 사용해서 PIM 수준에서 실제 디자 


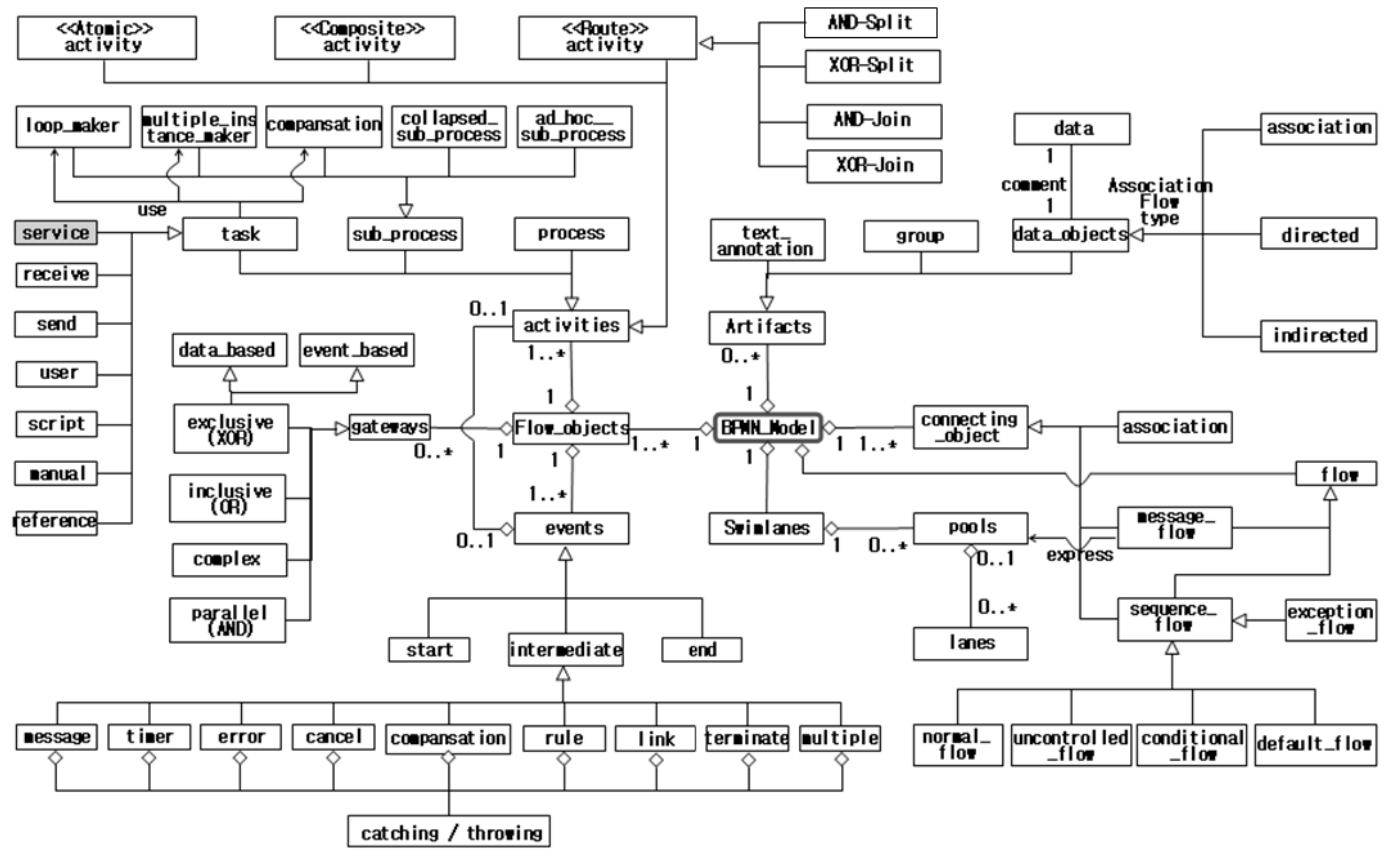

Fig. 4. BPMN metamodel

Table 2. Criteria and method to build XL-BPMN Metamodel

\begin{tabular}{|c|c|c|c|}
\hline $\begin{array}{l}\text { Appl. Arch } \\
\text { Patt. } \\
\text { MDA Type }\end{array}$ & Client (View) & $\begin{array}{l}\text { Business } \\
\text { (Controller) }\end{array}$ & Data (Model) \\
\hline CIM & $\begin{array}{l}\text { O Basic domain business mc } \\
\text { o Designing the layered BPI } \\
\text { granularity of modeling t: } \\
\text { - system, domain task, ser } \\
\text { o The construction of metar } \\
\text { model }\end{array}$ & $\begin{array}{l}\text { deling } \\
\text { IN models according to diffe } \\
\text { rget } \\
\text { ice } \\
\text { odel with essential modelin }\end{array}$ & ferent levels of \\
\hline \multirow[t]{2}{*}{ PIM } & \multicolumn{3}{|c|}{$\begin{array}{l}\text { o Specific domain business modeling which makes CIM BPMN model with } \\
\text { service-sized target domain } \\
\text { o Building the metamodel with concrete modeling elements of BPMN model } \\
\text { - process, sub-process, task, and etc } \\
\end{array}$} \\
\hline & $\begin{array}{l}\text { o Identification of Client } \\
\text { service for one service } \\
\text { target }\end{array}$ & $\begin{array}{l}\text { o Identification of } \\
\text { Business service for one } \\
\text { service target }\end{array}$ & $\begin{array}{l}\text { O Identification of } \\
\text { Data service for one } \\
\text { service target }\end{array}$ \\
\hline PSM & $\begin{array}{l}\text { o Making the model by } \\
\text { using the GUI modeling } \\
\text { elements with platform } \\
\text { dependent } \\
\text { (BPEL and Java target) }\end{array}$ & $\begin{array}{l}\text { o Making the model by } \\
\text { using the Business } \\
\text { modeling elements with } \\
\text { platform dependent } \\
\text { (BPEL and Java target) }\end{array}$ & $\begin{array}{l}\text { o Making the model } \\
\text { by using the DB } \\
\text { modeling elements } \\
\text { with platform } \\
\text { dependent } \\
\text { (BPEL and Java target) }\end{array}$ \\
\hline
\end{tabular}

인시 생성되는 모델은 Client service BPMN 모델, Business $\operatorname{logic} \mathrm{BPMN}$ 모델 및 Data service $\mathrm{BPMN}$ 이 작성된다.

여기서, "service" 수준에서 MVC 패턴 적용의 방법은 Fig. 5와 같다.

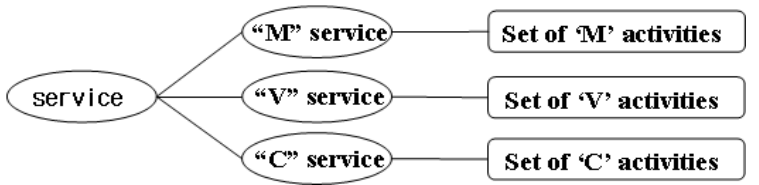

Fig. 5. Applying of MVC pattern at the "service" level

$\mathrm{BPMN}$ 모델을 계층적 모델링을 제공하기 위한 Layered MetaModel(L-MM)[19]은 다음과 같이 정의한다.

[정 의 3-1] (Layered Metamodel). A L-MM은

$\mathrm{L}-\mathrm{MM}=\{n, A L, M E C l a, R e l, M u l, S T, L a b\}$ 로 구성한
다: (i) $n$ 은 metamodel name (CIM/PIM/PSM BPMN $\mathrm{L}-\mathrm{MM}$ ); (ii) $A L$ 은 계층적 $\mathrm{BPMN}$ Model의 추상화 수준; (iii) $\mathrm{MDD}$ 와 $\mathrm{MVC}$ 가 체화된 $\mathrm{BPMN}$ Model 구조물 modeling element classes인 유한집합 MECla; (iv) MECla 들 간의 relation $R e l \subseteq(M E C l a \times M E C l a) ;(v) M E C l a$ 들 간의 대응수 $\mathrm{Mul} \subseteq(\mathrm{MECla} \times \mathrm{MECla})(*, 1 . *, \cdots)$; (vi) $\operatorname{MECla}(\mathrm{i}, \mathrm{j}, \mathrm{k}, \cdots$ )에 대한 스테레어타입 클래스 $S T$, 여기 서 스테레오타입은 플랫폼 타입, 크기 수준 등; (vii) MECla 들 간의 관계 라벨 $S T$ (옵션).

따라서, XL-BPMN 메타모델은 [정의 3-1]에 의해 정의 된 $\mathrm{L}-\mathrm{MM}$ 의 인스턴스(instance)로 다음과 같이 정의된다.

[정의 3-2] (XL-BPMN Metamodel). XL-BPMN Metamodel은 다음의 요소들로 구성한다. (1) $\mathrm{XL}-B P M N$ Metamodel은 메타모델 이름; (2) CIM, PIM, PSM은 추상 화 수준; (3) process, activities, task 등은 BPMN 모델링 요소인 클래스들; (4) association, inheritance, aggregation 의 3 개 관계들; (5) $1,0.1,0 . *, 1 . . *$ 의 4개 대응수; (6) client service, business_logic service, data service 등은 스테레오 타입된 클래스들; (7) express, comment의 관계라벨들.

한편, $\mathrm{XL}-\mathrm{BPMN}$ 메타모델에 $\mathrm{MDA} / \mathrm{MVC}$ 패턴 그리고 크기에 의해 새로이 확장되는 모델링요소들에 대한 프로파 일을 정의한 것이 Table 3 이다. Table 3 은 기존의 BPMN 모델이 가진 모델링 요소에 "서비스 유형"과 모델링 대상의 "크기"(Fig. 2 참조), "MVC 패턴", 그리고 액티비티를 수행 하는 "행위자"들에 관련된 모델링 요소들을 추가한 것을 나 타낸다. 


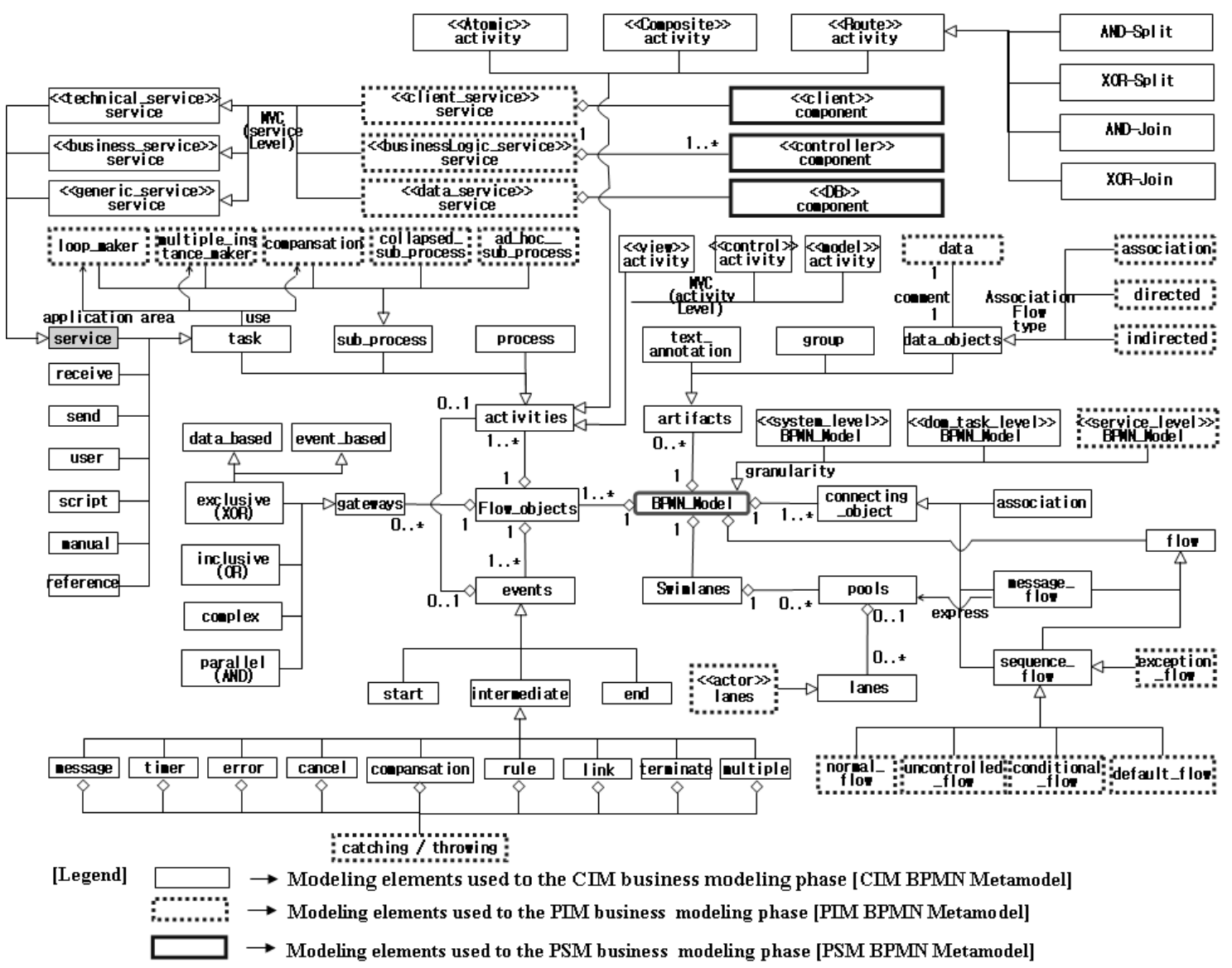

Fig. 6. XL-BPMN metamodel

Table 3. Profile of extended XL-BPMN modeling element

\begin{tabular}{|c|c|c|c|}
\hline \multicolumn{2}{|r|}{ Section } & \multirow{2}{*}{ Description } & \multirow{2}{*}{ Representation } \\
\hline Type & Modeling element & & \\
\hline \multirow{3}{*}{ Service } & generic service & $\begin{array}{l}\text { Common and generic service in } \\
\text { specific domain task level }\end{array}$ & Stereotype \\
\hline & business service & $\begin{array}{l}\text { Business service in specific } \\
\text { domain task level }\end{array}$ & Stereotype \\
\hline & technical service & $\begin{array}{l}\text { Technical or software service in } \\
\text { specific domain task level }\end{array}$ & Stereotype \\
\hline \multirow{3}{*}{ MVC } & client service & $\begin{array}{l}\text { The Service for handling user } \\
\text { interface in specific domain task }\end{array}$ & Stereotype \\
\hline & \begin{tabular}{|l} 
business logic \\
service
\end{tabular} & $\begin{array}{l}\text { The Service for handling business } \\
\text { logic in specific domain task }\end{array}$ & Stereotype \\
\hline & data service & $\begin{array}{l}\text { The Service for handling data } \\
\text { in specific domain task level }\end{array}$ & Stereotype \\
\hline \multirow{3}{*}{ Size } & system & $\begin{array}{l}\text { Generating the BPMN model } \\
\text { with system-sized granularity }\end{array}$ & Stereotype \\
\hline & domain task & $\begin{array}{l}\text { Building the BPMN model } \\
\text { with domain task-sized } \\
\text { granularity }\end{array}$ & Stereotype \\
\hline & service & $\begin{array}{l}\text { Making the BPMN model } \\
\text { with service-sized granularity }\end{array}$ & Stereotype \\
\hline Behavior & actor & $\begin{array}{l}\text { Separated representation of each } \\
\text { actor by using swimlane }\end{array}$ & Stereotype \\
\hline
\end{tabular}

이러한 확장된 모델링 요소들을 Fig. 4 의 BPMN 메타모 델에 반영하여 계층적으로 정의한 확장된 $\mathrm{XL}-\mathrm{BPMN}$ 메타 모델이 Fig. 6이다. Fig. 6은 모델링 단계에 고려한 CIM/ $\mathrm{PIM} / \mathrm{PSM} \mathrm{BPMN}$ 메타모델을 보여준다. 각 메타모델들은 개발의 추상화 수준 및 $\mathrm{MDA} / \mathrm{MVC}$ 에 부합하는 확장된 모 델링 요소들로 정의한다. $\mathrm{MVC}$ 패턴에 의한 모델링 요소는 "service"에 대해 각각 "MVC"로 분리하여 스테레오타입으
로 표현한다. 가령, ' $\mathrm{V}^{\prime}$ 에 의해 GUI service와 GUI activity 로 표현한다.

3.3 메타모델 기반 BPMN 서비스 모델링 프로세스

본 논문의 접근은 $\mathrm{MDA}$ 와 $\mathrm{MVC}$ 가 결합된 모델링을 위한 아케텍쳐에 초점을 둔다. 그 이유는 관점(view)에 따라 생성 된 산출물에 대해 service 수준에서, model 수준에서, 그리 고 component 수준에서 다양한 크기 대상으로 재사용성을 향상시키기 위함이다. 그래서, $\mathrm{MVC}$ 패턴은 개발의 추상화 정도를 고려한 $\mathrm{MDA}$ 패러다임을 지향하며, 도메인 의존성 과 구현 플랫폼 환경의 적용여부에 의존해서, 어플리케이션 모델들을 분리하여 구축할 수 있는 2 계층(CIM/PIM) 서비스 모델링 단계들로 정의한다. 본 고에서 $\mathrm{PSM}$ 수준을 위한 모 델링 단계의 프로세스는 포함하지 않았다. 왜냐하면, SOA 기반 $\mathrm{M} / \mathrm{V} / \mathrm{C}$ 별 컴포넌트 모델, BPEL 모델 및 $\mathrm{WSDL}$ 명세 가 결합된 메타모델과 프로세스의 정립 그리고 이질적 모델 간 변환 알고리즘 등의 작업이 요구되는 또 다른 이슈가 되 기에 후속연구에서 제시할 것이다. 이에, 2 단계 $\mathrm{BPMN}$ 모델 링 아키텍쳐 및 프로세스는 다음과 같이 정의한다.

[정의 3-3] (BPMN-모델링 아키텍쳐). $\mathrm{BPMN}$ 모델링 아 키텍쳐 $\mathrm{B}-\mathrm{MA}=\{M D A \cup M V C\}$ 는 다음과 같이 구성한 
다. (i) model-driven architecture $M D A$ 접근, 여기서 $\mathrm{MDA}$ $=\{$ For BPMN models $\mid$ \{CIM-BPMN-Model(Bus-Sermp) $\} \cup\{$ PIM-BPMN-Model(Sys-Ser-mp) $\}$, Bus-Ser$\mathrm{mp}$ 는 비즈니스 서비스 모델링 단계이며, Sys-Ser-mp는 시 스템 서비스 모델링 단계를 각각 의미한다; (ii) 어플리케이 션 아키텍쳐 $M V C$ 패턴, 여기서 $\mathrm{MVC}=\{$ For $\mathrm{BPMN}$ models $\mid$ \{View-Service\} $U$ \{Controller-Service $U$ \{Model-Service\}\}이다.

[정의 3-4] (서비스 생성: SG). 단위 cell service를 $\mathrm{B}-\mathrm{MA}$ 에서 작성되는 모델 단위의 산출물이라 하자. 각 서 비스 cell은 서비스 집합의 하나이다. $\mathrm{SG}=\{\mathrm{For} \mathrm{BPMN}$ models $\mid\{\{\mathrm{CIM}\} \wedge\{\mathrm{PIM}\}\} \cup\{\{\mathrm{M}\} \wedge\{\mathrm{V}\} \wedge\{\mathrm{C}\}\}$, 여기 서 $\{\{\mathrm{CIM}\} \cap\{\mathrm{PIM}\}\}=\varnothing$ and $\{\{\mathrm{M}\} \cap\{\mathrm{V}\} \cap\{\mathrm{C}\}\}=\varnothing$ (공집합). 즉, 한 개의 cell 서비스는 모든 type들에 대한 $\mathrm{MVC}$ 와 $\mathrm{MDA}$ 가 존재한다면 작성 가능하다.

[정의 3-5] (BPMN 모델링 프로세스: B-MP). BPMN 모 델링 프로세스는 $\mathrm{B}-\mathrm{MP}=(n, M P,-, I)$ 로 구성한다. (i) 비지니스 모델링 프로세스 이름 $n$; (ii) 모델링 단계들의 유 한집합 $M P$; (iii) 모델링 단계간의 프로세스 순서 관계 $\subseteq(M P \times M P)$; (iv) 나선형 프로세스 모델에 기반한 반복 흐름 $I$ (반복 \#1, 반복 \#2, $\cdots$ ).

[정의 3-6] (모델링 단계: $\mathrm{MP})$. 모델링 단계는 $\mathrm{MP}=(n$, $A C T, \rightarrow, W P$ )로 구성한다. (1) 모델링 단계의 이름 $n$ (비 지니스 서비스 $M P$, 시스템 서비스 $M P$ ); (2) 액티비티들의 유한집합 $\mathrm{ACT}, \mathrm{x}, \mathrm{y}, \mathrm{z} \in \mathrm{MP}$, 액티비티는 이전 액티비티 를 통한 입력물과 XL-BPMN 메타모델에 정의한 모델링요 소들을 사용해서 모델을 작성한다; (3) 전이 관계 $\rightarrow \subseteq$ $(A C T \times A C T)$, 관계 유형으로 previous/after 그리고 fork/ join를 갖는다; (4) 액티비티의 출력 혹은 산출물 $W P$.

상기 [정의 3-3]에서 [정의 3-6]에 의거하여, Fig. 7은
$\mathrm{MDA}$ 와 $\mathrm{MVC}$ 에 의한 비즈니스 서비스의 모델링 아키텍쳐 및 모델링 프로세스를 보여준다. 모델링 단계에 걸쳐 $\mathrm{MDA}$ 에 의해 생성되는 산출물들은 CIM BPMN business model 과 $\mathrm{PIM} \mathrm{BPMN}$ service model 이다. MVC pattern은 PIM $\mathrm{BPMN}$ 모델에 대해 application의 service architecture를 Client/Controller/Data로 분리, 구축된 BPMN Model을 Client service/View service/Controller service로 분리하여 디자인한다. 이러한 $\mathrm{MDA}$ 와 $\mathrm{MVC}$ 를 적용해서 계층적 $\mathrm{BPMN}$ 모델링 프로세스가 정립된다. 계층적 비지니스 모델 링 작업은 $\mathrm{MDA}$ 기반 개발 단계의 생명주기에 따라 상위의 추상적 모델링에서 하위의 구체적 모델링으로 디자인 해나 가토록 프로세스를 정립한다. Fig. 7에서 순번 1에서 7번에 이르는 활동은 Fig. 6에서 정의한 CIM/PIM XL-BPMN 메 타모델의 모델링 요소들을 사용해서 수행한다. 이것이 메타 모델에 기반한 모델링 프로세스가 수행됨을 의미한다.

이 프로세스는 단계에 걸쳐, 나선형의 반복적 생명주기로 구성하여, 지속적으로 모델이 개선되고 확장되는 특성을 갖 는다. 각 단계는 활동들로 조직화되고, 각 활동은 세부적 프 로세스 지침을 정의하며, 활동을 통한 산출물이 생성되고, 산출물간의 연계성을 가지도록 정립한다. 여기서, PIM 단계 에서 $\mathrm{BPMN}$ 모델을 $\mathrm{M}, \mathrm{V}$ 및 $\mathrm{C}$ 패턴에 의해 분리된 형태로 생성한다. 이 모델링 프로세스를 통한 $\mathrm{BPMN}$ 모델의 디자 인 과정은 비즈니스 서비스 모델링 단계에서 Fig. 6에서 정 의한 $\mathrm{CIM}$ 적용의 모델링 요소들(즉, Fig. 4 의 BPMN 기본 모델링 요소)을 가지고 "system" 대상 크기의 BPMN 모델 을 작성하고, 또한 이 모델을 구성하는 각 "domain task" (즉, 서비스 단위) 및 "service" 대상 크기의 CIM BPMN 모 델들을 생성한다. 이후, 시스템 서비스 모델링 단계에서는 $\mathrm{XL}-\mathrm{BPMN}$ 메타모델에서 정의한 PIM 모델링 요소들을 사 용해서, 이전 단계의 서비스별 각 $\mathrm{BPMN}$ 모델에 대해 $\mathrm{MVC}$ 패턴에 의해 각각 분리된 PSM BPMN 모델을 생성한다.

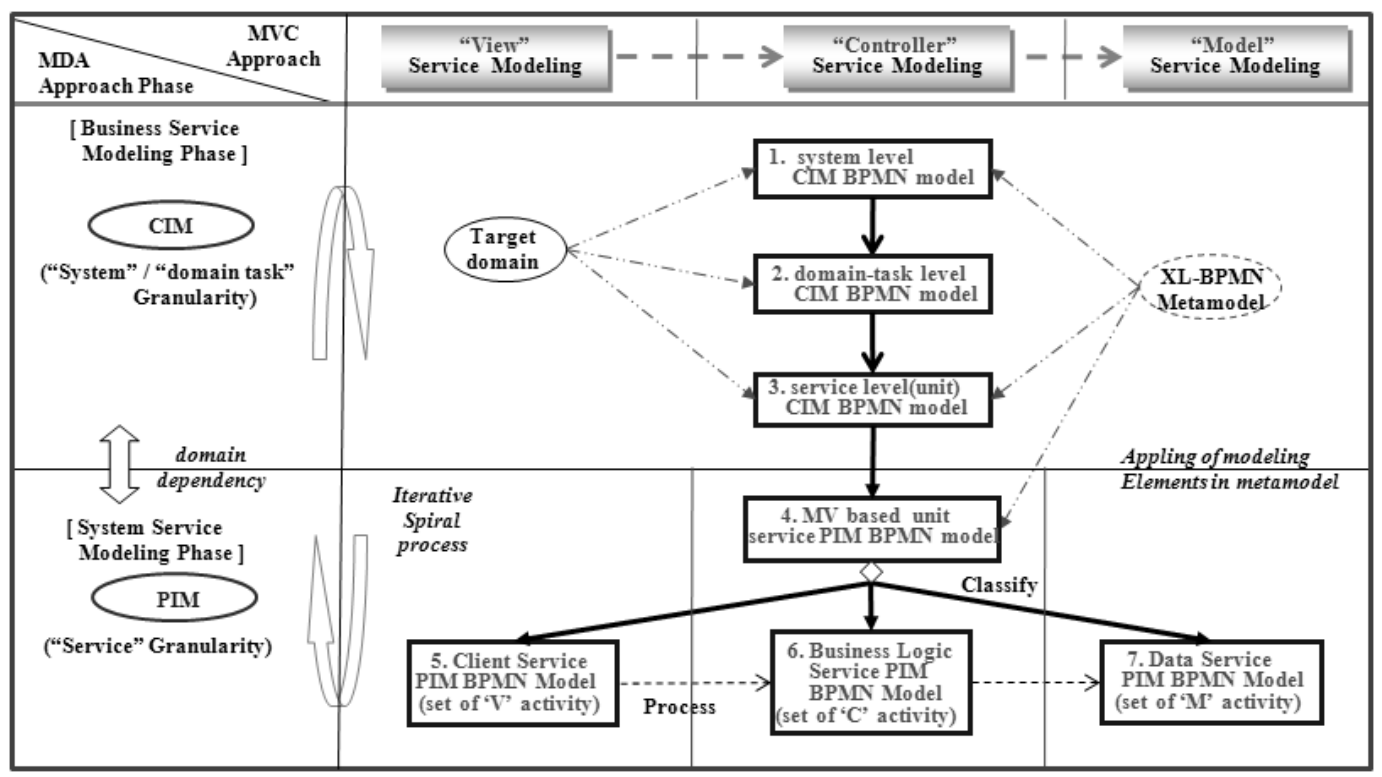

Fig. 7. Layered BPMN modeling architecture and process based on MDA/MVC 


\section{4. 적용사례: OSS}

제시한 계층적 $\mathrm{BPMN}$ 모델링 프로세스의 실효성을 보이 기 위하여, 온라인쇼핑몰시스템(OSS)을 대상으로 서비스 지 향의 BPMN 비즈니스 모델들을 기술한다.

\subsection{OSS의 Business service modeling phase}

비즈니스 서비스 모델링 단계는 전체 업무에 대한 도메인 의존의 개략적 비즈니스 제어흐름을 디자인한다. 이를 위해, 최상위 "system" 수준에서 단위 "service" 수준에 이르는 비 즈니스 업무를 모델링한다. 본 단계는 $\mathrm{MDA}$ 에 의한 $\mathrm{CIM}$ 모델을 작성하나, $\mathrm{MVC}$ 패턴은 적용되지 않는다. Fig. 6의 CIM BPMN Metamodel의 모델링요소들을 사용하고, Fig. 7 의 개발 프로세스에 따라, 최상위 수준에서 상위 "system" 기반 $\mathrm{CIM} \mathrm{BPMN}$ 모델을 나타낸 것이 Fig. 8이다. Fig. 8에 서 XL-BPMN 메타모델의 모델링 요소로 "sub_process" activity, "exclusive(XOR)" 등을 사용했다. 즉, 작은 사각형 내 “+”로 표기된 액티비티는 계층적으로 하부 $\mathrm{BPMN}$ 모델 을 가짐을 의미한다. 즉, 이들 간에는 복합 혹은 $\mathrm{sub}^{-}$ process의 관계를 가진다.

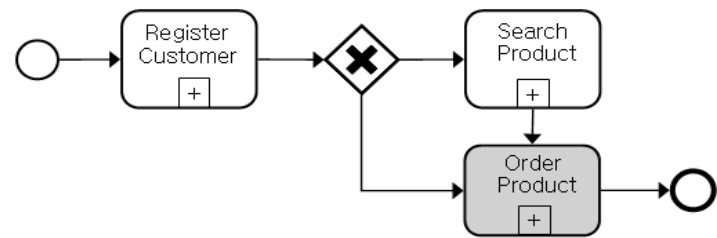

Fig. 8. CIM BPMN model at the "system" level

다음으로 중위 수준의 "domain-task" 기반 CIM BPMN 모델을 표현한 것이 Fig. 9이다. 이것은 Fig. 8의 "Order Product" 도메인 테스크를 대상으로 서비스 분류인 "technical/business/generic" 서비스의 모델링요소를 추가, 적용하여 작성했다.

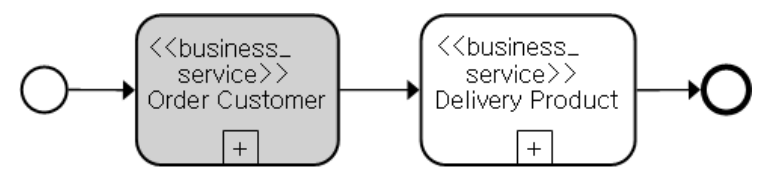

Fig. 9. CIM BPMN model at the "domain-task" level

또한, 하위 수준의 단위 셀(cell) "service" 기반으로 그림 9의 "Order Customer" 비즈니스 서비스를 계층적으로 복합 (composite)한 CIM BPMN 모델이 Fig. 10이다. 이 단위 서 비스가 서비스 지향의 $\mathrm{BPMN}$ 모델을 의미하고, 이를 통해 독립적 재사용의 단위 모델이 되는 것이다.

4.2 OSS의 System service modeling phase

본 모델링 단계는 business service modeling phase에서 식별된 단위의 셀 서비스별로 서비스 플랫폼에 독립적인

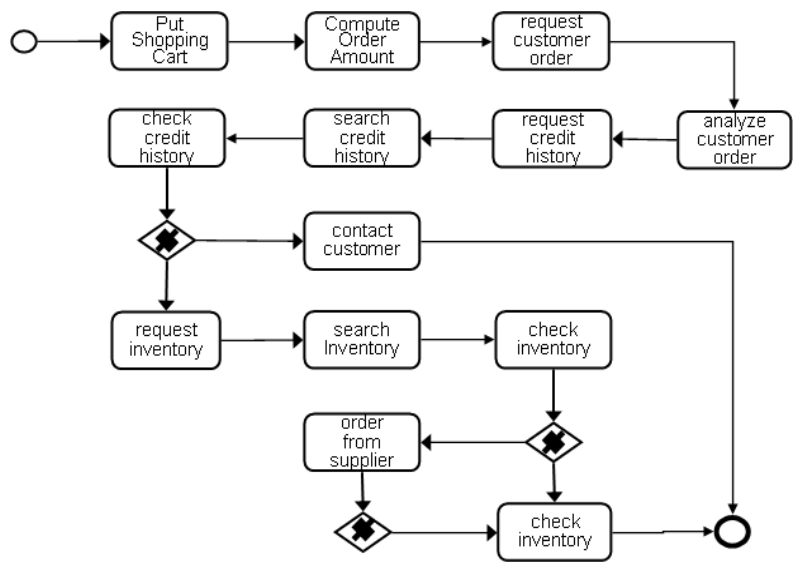

Fig. 10. CIM BPMN model at the unit "service" level

$\mathrm{PIM}$ 패턴 그리고 $\mathrm{MVC}$ 패턴을 적용하여 비즈니스 측면이 아닌, 시스템 측면에서 상세한 서비스 모델링을 수행한다. 따 라서, PIM XL-BPMN Metamodel의 확장된 모델링 요소들 (즉, "Client_service", "business_service" 및 "data_service") 을 사용해서 BPMN 모델을 디자인한다. Fig. 7의 모델링 프 로세스에 따라 각 서비스별로 $\mathrm{MVC}$ 기반 $\mathrm{PIM} \mathrm{BPMN}$ 모델 을 작성한다. 이에, Client service PIM BPMN 모델, Business logic service PIM BPMN 모델, 그리고 Data service PIM BPMN 모델들로 생성된다. 여기서, Business logic과 Data의 service PIM BPMN 모델은 EA(Enterprise Architecture) 기반의 application architecture와 DB architecture에 초석이 될 수 있다. Fig. 11은 MVC 기반 통 합 PIM BPMN 모델을 나타내고, Fig. 12는 Client service $\mathrm{PIM} \mathrm{BPMN}$ 모델을 각각 보여준다.

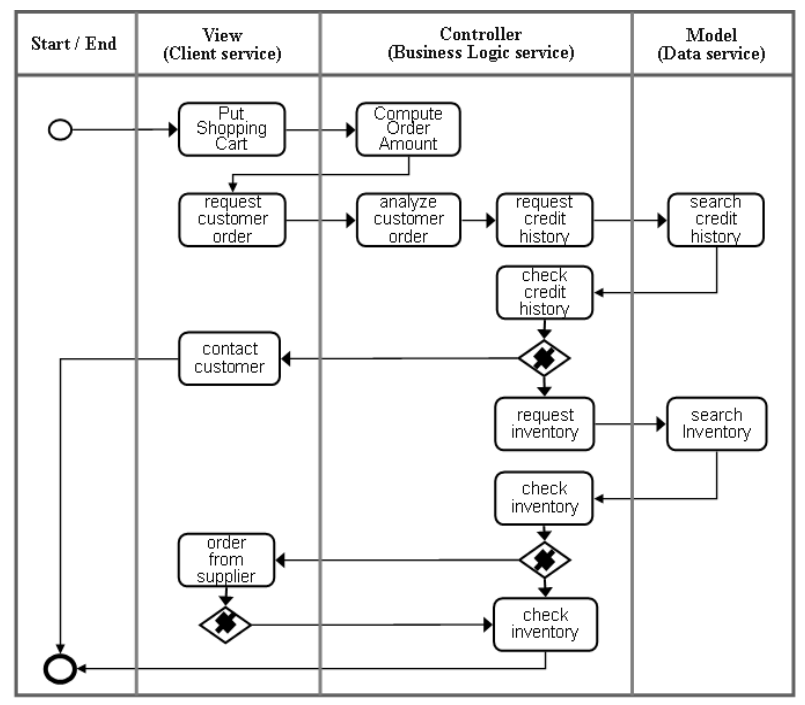

Fig. 11. MVC based Integrated service PIM BPMN model

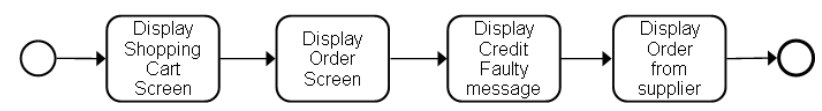

Fig. 12. PIM BPMN model focused on client service view 


\section{5. 평 가}

\section{1 기존 방법과의 비교평가}

제시 방법과 기존 방법간의 비교를 위해 $\mathrm{BPMN}$ 메타모 델, BPMN 모델링 프로세스 그리고 개발 노력 비용의 비교 메트릭스들을 가지고 분석한다.

\section{1) BPMN 메타모델}

$\mathrm{BPMN}$ 메타모델의 구성 측면에서, 제시 XL-BPMN 대비 해서 기존 $\mathrm{BPMN}$ 표준 $\mathrm{V} 1.0[6,20-21]$ 과 $\mathrm{BPMN}$ Beta $\mathrm{V} 2.0[7]$ 을 대상으로 비교한 것이 Table 4이다.

Table 4. Comparison in terms of formation of BPMN metamode

\begin{tabular}{|c|c|c|c|}
\hline Evaluation factor & $\begin{array}{c}\text { BPMN standard } \\
\text { V1.0 } \\
\text { metamodel }\end{array}$ & $\begin{array}{c}\text { BPMN Beta } \\
\text { V2.0 } \\
\text { metamodel }\end{array}$ & $\begin{array}{c}\text { Proposed } \\
\text { XL-BPMN } \\
\text { Metamodel }\end{array}$ \\
\hline $\begin{array}{c}\text { Cover level of entire } \\
\text { modeling phase }\end{array}$ & Low & High & High \\
\hline $\begin{array}{c}\text { Defining the layered } \\
\text { modeling elements by MDA }\end{array}$ & Middle & Middle & High \\
\hline $\begin{array}{c}\text { Specifying the separated } \\
\text { modeling elements by MVC }\end{array}$ & Low & Low & Middle \\
\hline $\begin{array}{c}\text { Additional scalability of } \\
\text { modeling element }\end{array}$ & Low & High & High \\
\hline $\begin{array}{c}\text { Providing a service } \\
\text { modeling element }\end{array}$ & Middle & Middle & High \\
\hline
\end{tabular}

Table 4에서, $\mathrm{BPMN}$ 표준 $\mathrm{V} 1.0$ 은 $\mathrm{BPD}$ (Business Process Diagram)의 핵심요소와 확장 요소들로 그 의미와 표기법을 정의하였으나, 모델 구조물의 메타모델은 제공하지 않는다. 즉, [20]은 BPMN 메타모델을 제시했고, [21]는 BPMN 모델 을 실행 수준에서 모델링요소들을 스테레오타입과 객체화하 여 메타모델을 제시했다. 최근, BPMN Beta V2.0은 BPD를 $\mathrm{BPMN}$ 이라 개칭하여, 핵심 및 확장 요소 그리고 요소들간 의 인프라 및 협력관계에 대한 구문을 메타모델로 정의하고, 요소들의 시멘틱을 제공한다. 그러나, $\mathrm{BPMN}$ 표준 V1.0은 메타모델을 정의하고 있지 않아, 각 평가 항목에서 낮은 수 준을 갖는다. 메타모델을 제공하는 $\mathrm{BPMN}$ Beta V2.0은 $\mathrm{MDA}$ 및 $\mathrm{MVC}$ 기반의 계층화된 모델링 요소들로 구성된 메타모델을 제공하지 않는다. 반면, 제시 XL-BPMN 메타모 델은 서비스 중심 그리고 $\mathrm{MDA} / \mathrm{MVC}$ 의 계층화된 모델링 요소들을 제공한다.

2) BPMN 모델링 프로세스

$\mathrm{BPMN}$ 모델링 프로세스 측면에서, BPDS-BB[5], MINERVA[16] 그리고 ARIS[17]를 대상으로 비교, 분석한 것이 Table 5이다. Table 5에서, 본 논문과 ARIS 방법은 서 비스 지향 패러다임에 따라 $\mathrm{MDA} / \mathrm{MVC}$ 기반의 $\mathrm{BPMN}$ 모 델링 방법을 다룬 것에 유사성을 갖는다. 그러나, ARIS는 계층화되고 $\mathrm{BPMN}$ 메타모델 기반의 모델링요소들을 사용한 프로세스를 제공하지 않는다. 이외, BPDS-BB와 MINERVA
방법들은 $\mathrm{MDA}$ 및 $\mathrm{MVC}$ 패턴에 의한 프로세스 제공이 부 족하다. 한편, 제시하는 메타모델을 사용하면, $\mathrm{BPMN}$ 모델 의 전체적 모델링 요소들간의 구문적 구조의 이해성을 향상 시킬 수 있으며, 메타모델에 의한 구축된 CIM과 PIM 모델 들간의 추적성 혹은 일치성을 검사가 가능해진다.

Table 5. Comparison of the details of BPMN modeling process

\begin{tabular}{|c|c|c|c|c|}
\hline Evaluation factor & BPDS-BB & MINERVA & ARIS & $\begin{array}{c}\text { Proposed } \\
\text { method }\end{array}$ \\
\hline Target business model & BPMN & BPMN & EPC & BPMN \\
\hline $\begin{array}{c}\text { Designing a model based } \\
\text { CIM, PIM pattern }\end{array}$ & No & No & Yes & Yes \\
\hline $\begin{array}{c}\text { Designing a layered model } \\
\text { based MVC }\end{array}$ & No & No & Yes & Yes \\
\hline $\begin{array}{c}\text { Designing a model using a } \\
\text { layered modeling elements } \\
\text { by development phase }\end{array}$ & No & PS & No & Yes \\
\hline Supporting case study & Yes & Yes & PS & No \\
\hline $\begin{array}{c}\text { Service oriented } \\
\text { model design }\end{array}$ & PS & Yes & Yes & Yes \\
\hline
\end{tabular}

[legend : Yes(support), No(not support), PS(Partial support)]

\section{3) 개발 노력비용 평가}

노력비용 측면에서, 시스템의 규모가 클수록 기존 방법에 비해 제시 방법이 많은 재사용 비즈니스 모델을 사용할 수 있기 때문에 좀 더 노력 비용을 절감할 수 있을 것이다. 반 면, 시스템의 규모가 작으면, 제시 방법은 재사용 모델을 생 성하기 위한 많은 모델링 활동을 수행하기에 기존 방법 대 비 더 많은 노력 비용이 요구된다.

유지보수 및 재사용 기반 개발 측면에서, 개발비용 평가는 Table 6 과 같다. Table 6에서, 제시 방법은 추상화 수준별 (MDA/MVC) 및 모델별 정형화된 메타모델의 모델링 요소 들을 사용하기에 기존 방법들보다 우수하다고 할 수 있다. 가령, 새로운 시스템의 구축에 대해, Fig. 7에서, 단위 서비스 수준에서 “6. Data Service PIM BPMN Model”가 상이할 경 우, 1 번에서 5 번에 이르는 즉, 기 작성된 "CIM $\mathrm{BPMN}$ Model"," Business Logic PIM BPMN Model"들을 재사용할 수 있기 때문에 그 만큼 개발 노력 비용을 절감할 수 있다.

Table 6. Evaluation of effort cost in case of maintenance and reuse based development

\begin{tabular}{|c|c|c|c|c|c|}
\hline \multicolumn{2}{|c|}{ Evaluation factor } & BPDS-BB & MINERVA & ARIS & $\begin{array}{c}\text { Proposed } \\
\text { method }\end{array}$ \\
\hline \multicolumn{2}{|c|}{ Modification cost } & High & High & Low & Low \\
\hline \multicolumn{2}{|c|}{ Maintenance cost } & High & High & Low & Low \\
\hline \multirow{2}{*}{$\begin{array}{c}\text { Reuse-ba } \\
\text { sed } \\
\text { developm } \\
\text { ent cost }\end{array}$} & $\begin{array}{c}\text { Extended } \\
\text { cost }\end{array}$ & High & High & Low & Low \\
\hline & $\begin{array}{c}\text { Reuse } \\
\text { cost }\end{array}$ & High & High & Low & Low \\
\hline
\end{tabular}

\section{2 재사용성 평가}

기존 방법들과 대비해서, 제시 방법을 적용해서 작성된 산출물 모델들의 재사용성 측면에서 정량적 평가를 보인다. 
재사용성은 $\mathrm{MDA} / \mathrm{MVC}$ 기반으로 작성된 $\mathrm{BPMN}$ 모델들 이 새로운 도메인의 $\mathrm{BPMN}$ 모델 구축시 재사용되는 가에 대한 척도이다. 제시한 계층적 메타모델과 모델링 프로세스 에 의해 다양한 추상화 수준 및 크기에서 재사용 될 수 있 음을 4장의 적용사례를 통해서 알 수 있다. 가령, 새로이 구 축되는 $\mathrm{BPMN}$ 모델이 PIM 수준 이하에서 상이할 경우, 이 전 단계의 산출물인 "system/domain-task/service" 수준에 서 작성된 $\mathrm{CIM} \mathrm{BPMN} \mathrm{모델들을} \mathrm{그대로} \mathrm{재사용할} \mathrm{수} \mathrm{있다.}$ 따라서, 제시한 $\mathrm{MDA} / \mathrm{MVC}$ 기반으로 작성된 $\mathrm{BPMN}$ 모델들 의 재사용성을 좀 더 향상시킬 수 있다. 재사용 가능 모델 수를 산정하는 방식은 다음과 같다.

- 산정 방법

- 재사용 가능 구축 모델 수 =

$\mathrm{CIM} / \mathrm{PIM}$ 모델 수(개발단계 수) x MVC 모델 수

- 모델링 과정에서 생성되는 재사용 모델 수들을 누적 하여 얻을 수 있다.

- 산정 수식

$$
\left.\bigcup_{(\mathrm{R})}^{\mathrm{Num}}=\sum_{\mathrm{i}=\mathrm{CIM}}^{\mathrm{PIM}} \text { (MDA model }\right)\left(\sum_{\mathrm{j}=\mathrm{M}}^{\mathrm{C}}(\text { MVC model })\right)
$$

상기의 산정 수식에 의거, 각 모델링 방법들과의 재사용 모델 수를 비교한 것을 Table 7에서 보여준다. BPDS-BB와 MINERVA에 대한 MDA 모델 수가 "1"인 이유는 그들 방 법이 $\mathrm{MDA}$ 와 $\mathrm{MVC}$ 에 의한 모델을 작성하지 않지만, 구축 대상 도메인의 비즈니스 모델로서 1 개의 모델을 생성하기 때문이다. 반면, $\mathrm{MDA}$ 모델 수 산정에 대해서, ARIS와 제시 방법은 CIM 모델 및 PIM 모델을 작성하기에 모델의 수가 "2"이 된다.

Table 7. Analysis of number of reusable model

\begin{tabular}{|c|c|c|c|c|}
\hline $\begin{array}{c}\text { Method/ } \\
\text { MDD technique }\end{array}$ & BPDS-BB & MINERVA & ARIS & $\begin{array}{c}\text { Proposed } \\
\text { method }\end{array}$ \\
\hline Number by MDA & 1 & 1 & 2 & 2 \\
\hline Number by MVC & 0 & 0 & 3 & 3 \\
\hline $\begin{array}{c}\text { Total number of } \\
\text { reuse-available } \\
\text { models (weight) }\end{array}$ & $1(20 \%)$ & $1(20 \%)$ & $5(100 \%)$ & $5(100 \%)$ \\
\hline
\end{tabular}

\section{6. 결 론}

현존 $\mathrm{BPMN}$ 비즈니스 모델링 방법들은 서비스 지향의 개발 그리고 $\mathrm{MDA}$ 와 $\mathrm{MVC}$ 에 기반한 계층적인 개발 프로세 스가 성숙되지 않았다. 본 논문은 $\mathrm{MDA}$ 와 $\mathrm{MVC}$ pattern에 의거한 서비스 지향으로 $\mathrm{BPMN}$ 모델을 계층적으로 모델링 할 수 있는 확장된 XL-BPMN 메타모델을 제시했다. 또한, 정형화된 메타모델의 모델링 요소들을 사용한 2 개 서비스 모델링 단계로 구축된 $\mathrm{BPMN}$ 모델링 프로세스를 정립했다. 이를 통해, 서비스 관점에서 초기 비지니스 모델링에서 플 랫폼 독립적인 서비스 디자인에 이르는 비지니스 모델링 방
법을 제시했다. 이로서, $\mathrm{BPMN}$ 기반의 비즈니스 프로세스 모델링에 대한 서비스 지향의 계층적 모델의 구축을 제공할 수 있다. 따라서, $\mathrm{BPMN}$ 비지니스 모델의 모듈성 강화에 따 른 고 품질화와 재사용성을 제고시킬 수 있다. 아울러, 비즈 니스 모델을 $\mathrm{MVC}$ 패턴에 의해 분리하여 모델링함으로서 어느 한쪽의 변경시, 그 수정의 영향을 최소화시켜준다. 아 울러, $\mathrm{BPMN}$ 모델의 서비스 표현력 확장 및 계층적 접근에 의한 비즈니스 서비스의 복잡성 해소할 수 있다. 향후 연구 로서, $\mathrm{XL}-\mathrm{BPMN}$ 모델의 $\mathrm{PSM}$ 수준의 모델링 프로세스, $\mathrm{BPEL}, \mathrm{WSDL}$ 이 가미된 $\mathrm{SOA}$ 기반 비즈니스-소프트웨어 통 합 모델링 프레임워크 및 프로세스, 이들 이질적 모델간 변환 알고리즘의 개발을 후속할 것이다.

\section{참 고 문 헌}

[1] Pete Rivett, Applying MDA Standards to bring the A to SOA, Adaptive company[Internet], http://www.omg.org/news/ meetings/workshops/SOA_MDA_WS_Workshop_CD/05-3_ Rivett_Revised.pdf, 2006. 3.

[2] J. Touzi, F. Benaben, H. Pingaud, "Prototype to Support Morphism between BPMN Collaborative Process Model and Collaborative SOA Architecture Model," in Enterprise Interoperability III Springer London, pp.145-157, 2008.

[3] Olaf Zimmermann, Jana Koehler, Frank Leymann, Architectural Decision Models as Micro-Methodology for Service-Oriented Analysis and Design [Internet], http:// citeseerx.ist.psu.edu/viewdoc/download?doi.10.1.1.85.3974\&re p=rep1\&type=pdf, 2006.

[4] S. H. Lee, D. S. Kang, C. Y. Song, D. K. Baik, "A Method of Test Case Generation using BPMN-based Model Reduction for Service System," The Kips Transactions:part D, Vol.16D, No.4, pp.595-612, 2009.

[5] M. Juric, K. Pant, "Business Process Driven SOA using BPMN and BPEL," PACKT Publishing, 2008. 8.

[6] OMG, Business Process Model and Notation, V1.1[Internet], http://www.omg.org/bpmn/Documents/BPMN_1-1_Specifica tion.pdf, 2008. 1.

[7] OMG, Business Process Model and Notation(BPMN) V2.0[Internet], http://www.omg.org/spec/BPMN/2.0/Beta2/ PDF, 2010. 6.

[8] Kerstrn pfitzner, Gero Decker, Oiver Kopp, Fank Leymann, Web Service Choreography Configurations for BPMN [Internet], http://www.epc-editor.org/pub/Public/GeroDecker/ wesoa2007-bpmn2bpel4chor.pdf, 2007.

[9] National Information Society Agency(NIA), Development of a Guideline forImplementing BPMS based on BPM Standards[Internet], NCA IV-RER-05011, http://www.nia. or.kr/bbs/board_view.asp?BoardID=201111281321074458\&id= 2396\&Order $=010200 \&$ search_target $=\&$ keyword $=\&$ Flag $=01000$ 0, 2005. 12

[10] Joaquin Miller and Jishnu Mukerji., MDA guide version 1.0.1[Internet], http://www.omg.org/cgi-bin/doc?omg/03-06 -01, Object Management Group, Technical Report, 2003. 
[11] G. M. Kapitsaki, D. A. Kateros, G. N. Prezerakos, and I. S. Venieris, "Model-driven development of composite context-aware web applications," Information and Software Technology, Vol.51, No.8, pp.1244-1260, 2009.

[12] H. G. Min and S. D. Kim, "Process and Techniques to Generate Components in MDA/CB-PIM for Automation," in Proceedings of ICCSA'06 of the 2006 international conference on Computational Science and Its Applications, Vol.Part IV, 2006, pp.736-745.

[13] A. Joukhadar, "EliXir: a framework for Building e-business applications," in proceedings of the ICTTA 2008, 2008, pp. $1-5$.

[14] H. S. Cheo, Object oriented CBD Development Bible, Hanbit Media, 2003.

[15] Mike Ormerod, Defining the OPENEDGE® reference architecture presentation: Model-view-controller pattern [Internet], http://communities.progress.com/pcom/docs/DOC14628, 2009.

[16] Andrea Delgado, Francisco Ruiz, Ignacio Guzmán, and Mario Piattini, A Model-driven and Service-oriented framework for the business process improvement[Internet], http:// www.si-journal.org/index.php/JSI/article/viewFile/55/41, 2010.

[17] Sebastian Stein, Modelling Method Extension for Service-Oriented Business Process Management[Internet], Doctor's dissertation, http://sebstein.hpfsc.de/publications/ stein2009phd.pdf, 2009.

[18] C. Y. Song, E. S. Cho, "A PIM/PSM Component Modeling Technique based on 2+1 View Integrated Metamodel," The Kips Transactions:part D, Vol.16D, No.3, pp.381-394, 2009. 6.

[19] C. Y. Song, E. S. Cho, and C. J. Kim, "AN INTEGRATED GUI-BUSINESS COMPONENT MODELING METHOD FOR THE MDD-AND MVC-BASED HIERARCHICAL DESIGNS”, IJSEKE, Vol.21, No.3, pp.447-490, June, 2011.

[20] ebpml, BPMN 1.0 Metamodel[Internet], http://www.ebpml. org/wsper/ wsper/bpmn1.0.jpg, 2007.

[21] OMG, BPMN Execution Level Metamodel[Internet], http://www.bpmn.org/Documents/NWG-2002-01-07R6_BP MN_Metamodel.pdf, 2002.

[22] K. W. Kim, J. W. Lee, J. H. Son, "Design Anomalies in the Business Process Modeling," Journal of KIISE : Computing Practices and Letters, Vol.14, No.9, pp.850-863, 2008. 12.

[23] J. Y. Sul, J. O. Bak, H. S. Kim, Y. J. Sin, J. K. Jang, C. H. Bak, T. I. Kim, J. H. Son, "Validation Checking Mechanisms of Business Processes", Vol.14, No.9, Proceedings of the Korea Institute of Information Scientists 2006 autumn conference, Vol.33, No.2, 2006. 10.

[24] S. W. Kang, D. H. Lee, Y. W. Ahn, "Extending the Abstraction Capability of BPMN by Introducing Vertical Abstraction" The KIPS Transactions, Vol.16, No.2, 2009. 4.

[25] A. Rodriguez, E. Fernandez-medina, and M. Piattini, "A BPMN Extension for the Modeling of Security Requirements in Business Processes", IEICE TRANS. INF. \& SYST., Vol.E90-D, No.4, pp.745-752, 2007. 4.
[26] Stephen A. White, Using BPMN to Model a BPEL Process[Internet], IBM BPTrends, http://w.bptrends.com/ publicationfiles/03-05\%20WP\%20Mapping\%20BPMN\%20 to\%20BPEL-\%20White.pdf, 2005. 3.

[27] Chun. Ouyang, Wil Aalst, Marlons, Arthur, Translating BPMN to BPEL[Internet], http://eprints.qut.edu.au/3615/, 2006. 7.

[28] UN/CEFACT, UN/CEFACT Modeling Methodology (UMM) User Guide CEFACT/TMG/093 [Internet], http://www. unece.org/cefact/umm/UMM_userguide_220606.pdf, 2003. 9 .

[29] B. Hofreiter1, C. Huemer1, P. Liegl2, R. Schuster2, and M. Zapletal3, UN/CEFACT' Modeling Methodology (UMM): A UML Profile for B2B e-Commerce[Internet], http://www. ec.tuwien.ac.at/ ${ }^{\sim}$ zapletal/pub/A_UML_Profile_For_B2B_eCo mmerce.pdf, 2007.

[30] Victor. E. Sanvido, AN INTEGRATED BUILDING PROCESS MODEL[Internet], http://www.engr.psu.edu/ae/ cic/publications/TechReports/TR_001_Sanvido_1990_IBPM. pdf, 1990.

[31] Ang Cheng-Leong; Khoo Li Pheng; Gay Robert Keng Leng, IDEF*: a comprehensive modelling methodology for the development of manufacturing enterprise systems[Internet], int. j. prod. res., Vol.37, No.17, http://www.plus.ie/bpr/ papers/BPR\%20Modelling.pdf, 1999.

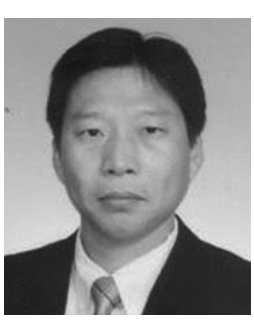

\section{송 치 양}

e-mail : cysong@knu.ac.kr 1985년 한남대학교 전자계산학과(학사) 1987년 중앙대학교 전자계산학과(공학석사) 2003년 고려대학교 컴퓨터학과(이학박사) 1990년 2005년 KT 중앙연구소 책임연구원 2005년 2008년 상주대학교 소프트웨어 공학과 조교수

2008년 현 재 경북대학교 컴퓨터정보학부 부교수 관심분야: 서비스 지향 모델링, 비즈니스-소프트웨어 통합 디자인, CBSE

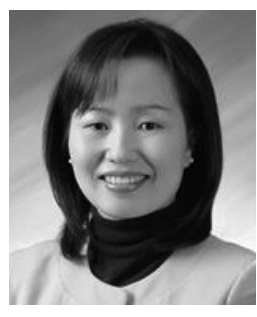

조 은 숙

e-mail :escho@seoil.ac.kr 1993년 동의대학교 전산통계학과(학사) 1996년 숭실대학교 컴퓨터학과(공학석사) 2000년 숭실대학교 컴퓨터학과(공학박사) 2000년 2005년 동덕여자대학교 정보학부 강의전임교수

2005년 현 재 서일대학 컴퓨터소프트웨어과 부교수 관심분야:CBSE, Embedded Software, Web Service, SOA, Service-Oriented Computing 